\title{
Case based gaming to increase efficiency in global planning processes by multimedia support
}

\author{
H. Augustin \\ Institute of Manufacturing Engineering and Production \\ Management FBK, University of Kaiserslautern, P.O. Box 3049, \\ 67653 Kaiserslautern, Germany, Tel. ++49.631.205.4281, \\ Fax.++49.631.205.3304,e-mail:augustin@cck.uni-kl.de
}

\begin{abstract}
Globalization and networking becomes a major issue in factory planning processes. At the same time, information and communication technologies are available which can fasten this process and increase the efficiency of global networking. To teach students and company's employees the handling of these new technologies a case based gaming approach is necessary due to the interaction in planning processes using different information and communication technologies.
\end{abstract}

\section{Keywords}

Factory planning, case study, information and communication technology

\section{$1 \quad$ INTRODUCTION}

The increasingly turbulent economic environment forces companies to continuously improve and constantly innovate of their structures and processes. This is reinforced by the growing trend towards globalization, which is the main reason for building up networks (Warnecke and Augustin, 1996). The process of organization design in the field of factory planning is getting more and more complex, mainly because of the 
rapidly developing technology and the distribution of resources within networks. Thus, the diversity and dynamics of design processes is steadily increasing.

Also, there is a fast development of information and communication technology (ICT). These new technologies can change the method of communicating in networks and create new structures and processes (Augustin and Förster, 1996).

Factory planning especially will change dramatically through the implementation of ICT in its international surrounding (figure1). Many firms are not aware of this potential to increase their effectiveness, because the work within the networks to solve complex problems as well as the usage of ICT to support networking are only partly implemented in tertiary education. To ensure this knowledge transfer into the companies a special teaching concept has to be implemented in tertiary education: Teaching of theoretical knowledge and the usage in the surrounding of real life situation has to be trained.

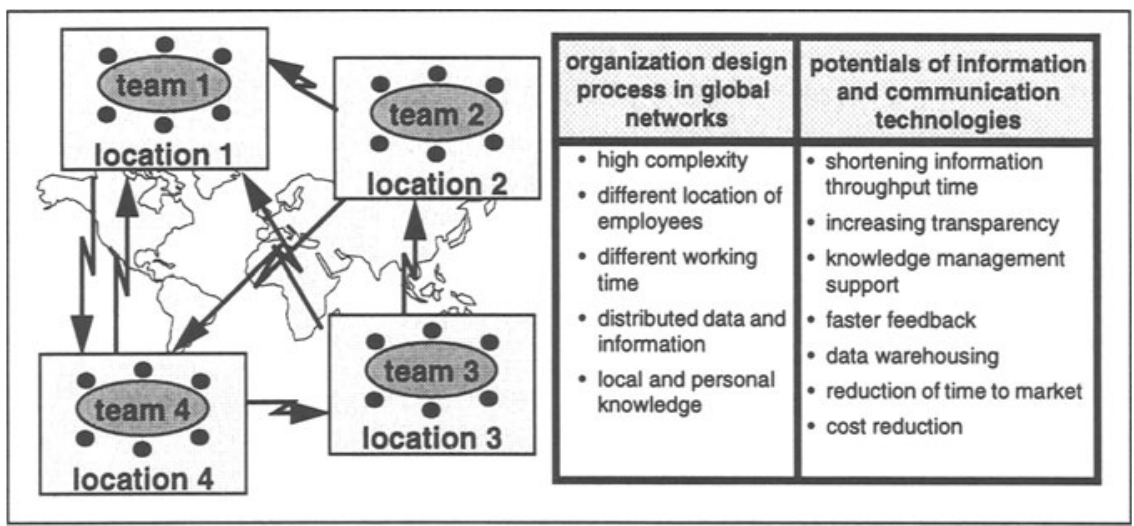

Figure.1: New requirements within global organization design processes and related potentials of ICT.

\section{GOALS}

To cope with the planning and handling of complex systems a game consisting of different teaching elements was developed, which is now used in tertiary education. This case-based game MinePlan (Multimedia Integrated Network Planning) is designed to eliminate the deficiencies in tertiary education mentioned in chapter 1 and aims at the following:

- The design of a plant-layout based on real life data creates a very realistic scenario and gives the student the experience of real engineering work.

- The process of team oriented problem solving of complex tasks in a short time is being trained, thus building up social competence. 
- The gathering of distributed knowledge and the team oriented usage of knowledge is being trained through the implementation of an information system for knowledge management by the group.

- The usage of modern ICT is being taught.

- The students have to evaluate which form of ICT usage is the most effective for a particular planning procedure or a particular form of communication.

MinePlan is based on a special teaching structure which includes a various number of teaching methodologies (figure 2):

- Theoretical lessons in the subject of work structuring and logistics design.

- Practical training in using multimedia ICT.

- Exercises to support the understanding of the transformation of theoretical knowledge for practical problem solving.

- A compact course that will enlarge the knowledge transfer in a complex planning situation within an internationally mixed planning group.

- Excursion to the company (real visit or video show) which provided the real life data of the compact course.

\begin{tabular}{|l|l|}
\hline Work Structuring & $\begin{array}{l}\text { Compact Course } \\
\text { Definitions }\end{array}$ \\
Planning of an axle pre-assembly segment \\
in the commercial vehicle production. \\
Main Tasks: \\
Tasks and methods of work structuring \\
$\square$ Work structuring and layout design
\end{tabular} $\begin{aligned} & \text { Work structuring and layout design } \\
& \text { Definition of logistic components and } \\
& \text { systems } \\
& \text { Personnel planning }\end{aligned}$

Figure 2: Contents of the teaching concept. 
The compact course is the main part of the teaching concept of MinePlan where the theoretical know-how has to be adapted to a real life planning situation and where the students have to make extended use of multimedia ICT to work within the distributed planning team. The planning process is related to the real life planning of a pre-assembly area of a heavy vehicle producer with an additional logistic scenario of supplier interaction. The teams have to develop a new factory and a logistic concept which will be evaluated in comparison to the solutions of other teams and presented at the end of the compact course.

\section{4}

\section{USAGE OF ICT}

As the teams are placed in different locations, the students have to make extensive use of communication tools such as video conferencing, application sharing, e-mail, telephone, fax etc. (Dier and Lautenbach, 1994; Lewe, 1995).

The support through ICT is based upon the tools shown in figure 3 (Bauerfeld, 1995), only a workflow management system (WFMS) is not used due to the fact that the planning process is based on a lot of ad-hoc decisions and therefore is not well structured enough to be implemented in a WFMS.

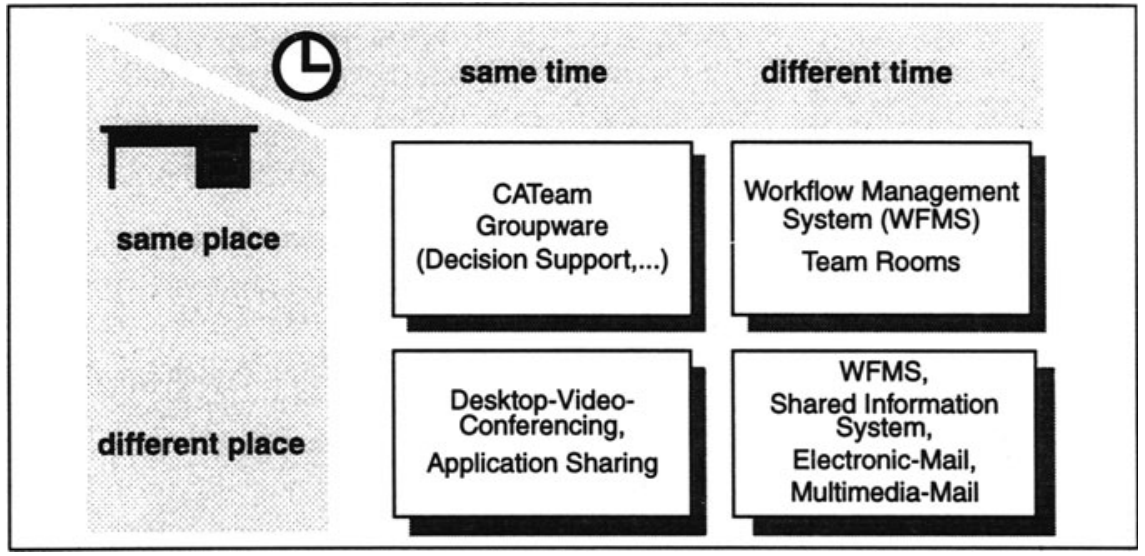

Figure 3: Functionality of CSCW technology.

The basic data for the compact course is provided by a database using a WWWBrowser as front-end. However, certain data is only accessible for the student playing the appropriate role in the game. Logistics data, for example, is only accessible for the student representing the logistics manager. With this, the students are forced to create a network based information system, making it possible for the whole group to access needed information to solve the given problems. 
The specific technologies which are used for the realization of MinePlan is shown in figure 4. To reduce the running costs, the video conferencing tools are based on Mbone technology using the internet technology and the transmission in the WIN (German Scientific Network).

\begin{tabular}{|c|c|c|c|}
\hline & Place & Tool & Description \\
\hline 1. Learning Material & $\begin{array}{l}\text { Kaiserslautern } \\
\text { (world wide access) }\end{array}$ & $\begin{array}{l}\text { WWW-Server } \\
\text { CBT via Internet or CD-ROM }\end{array}$ & $\begin{array}{l}\text { Documentation of theoretical } \\
\text { learning material } \\
\text { Computer Based Training for the } \\
\text { description of planning methods } \\
\text { and technical machinery and } \\
\text { tools used in the factory imple- } \\
\text { mentation }\end{array}$ \\
\hline 2. Discussion Forum & $\begin{array}{l}\text { Kaiserslautern } \\
\text { (world wide access) }\end{array}$ & News-Server & $\begin{array}{l}\text { Supervised News Group to dis- } \\
\text { cuss questions and ideas on the } \\
\text { subject }\end{array}$ \\
\hline 3. Basic Lessons & Kaiserslautern & & Frontal lessons \\
\hline 4. ICT-Exercises & Kaiserslautern & $\begin{array}{l}\text { Conferencing tools } \\
\text { - Video Conferencing (vic) } \\
\text { - Visual Audio Tool (vat) } \\
\text { - Session Directory (sd) } \\
\text { - White Board (wb) }\end{array}$ & $\begin{array}{l}\text { Lesson to learn the use of the } \\
\text { different ICT tools }\end{array}$ \\
\hline 5. Compact Course & $\begin{array}{l}\text { Kaiserslautern and } \\
\text { Darmstadt }\end{array}$ & $\begin{array}{l}\text { Conferencing tools } \\
\text { (see ICT exercises) }\end{array}$ & Planning in a distributed team \\
\hline 6. Working Material & $\begin{array}{l}\text { Kaiserslautern } \\
\text { (world wide access) }\end{array}$ & WWW-Server & $\begin{array}{l}\text { Data Sheets, Layout plans } \\
\text { personal information,... }\end{array}$ \\
\hline
\end{tabular}

Figure 4: Tools in the MinePlan environment.

\section{THE GAME}

In the first stage of development, which was oriented on an explorative prototyping process, the game MinePlan was hosted by the FBK (Institute of Manufacturing and Production Management) in Kaiserslautern and the GMD (German National Research Center for Information Technology) in Darmstadt. The groups were split into two teams, consisting of three and two participants, who were placed at two different locations (figure 5).

The groups had to perform both single-person tasks and joint-group tasks. The distributed information made interaction between the groups necessary, especially intasks like layout-planning. Therefore, conferencing tools were used extensively.

The supply of information was personalized using the WWW with passwords (figure 6). With this, each group could build up its own Knowledge Based Management System through joining their information, using the different methods and tools for CSCW. 


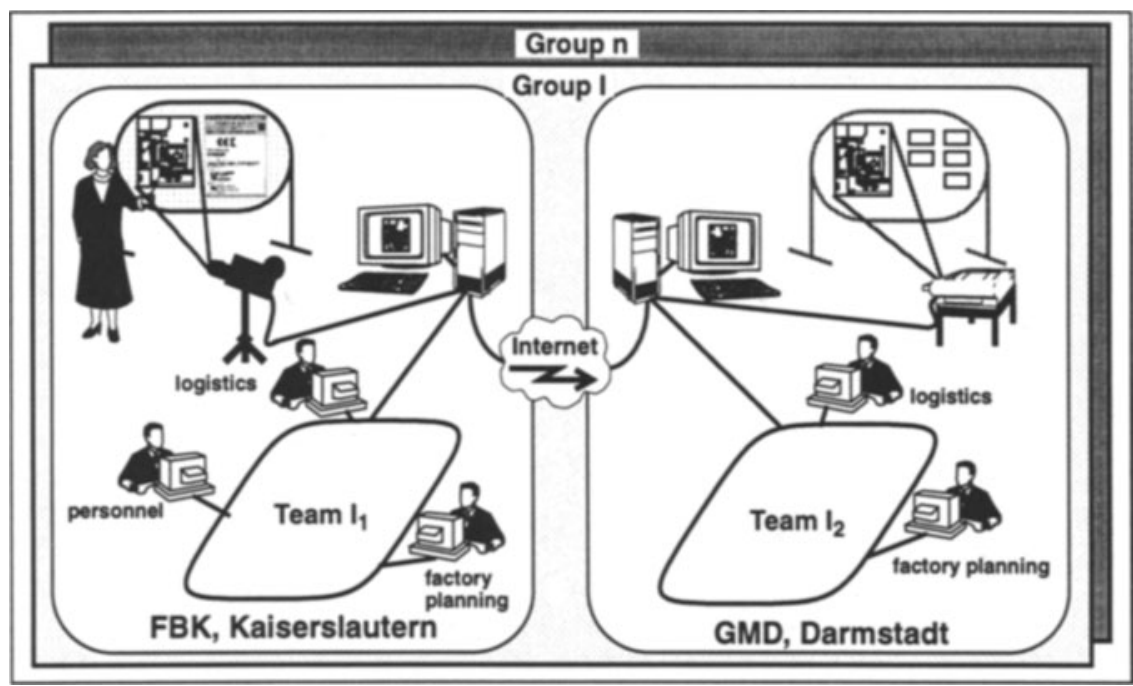

Figure 5: Information technology usage in the production design process.

\section{6}

\section{RESULTS}

The case-based game has already been played with groups joined together in one location and all the stated aims of the game have been reached (Augustin, 1996).

The compact course was initially held as ICT-oriented game in June 1997. Furthermore, the distance between Darmstadt and Kaiserslautern made face-to-face communication impossible, forcing the students to use communication tools.

For the evaluation of the game concept, the following points were evaluated during and after the compact course:

- Did the students manage to solve the problems without face-to-face communication?

The students were able to solve the problem in a much more efficient way. To communicate by video-conferencing or an application sharing session the students had to be will prepared. Due to this, the students came to faster decisions in each ICT supported meeting compared to the groups communicating face-to-face. The way of cooperating was more aim-oriented.

- How long did the group take to socialize? Did the usage of ICT help? In which situations would a face-to-face communication be helpful?

It took one day to socialize in the group. After this, the video signal was turned off most of the time and application sharing with audio-conferencing were the preferred tools. The usage of ICT helped, as mentioned above, to work in a more 
structured and efficient way. For the socializing process, a face-to-face meeting would have been preferred by the group.

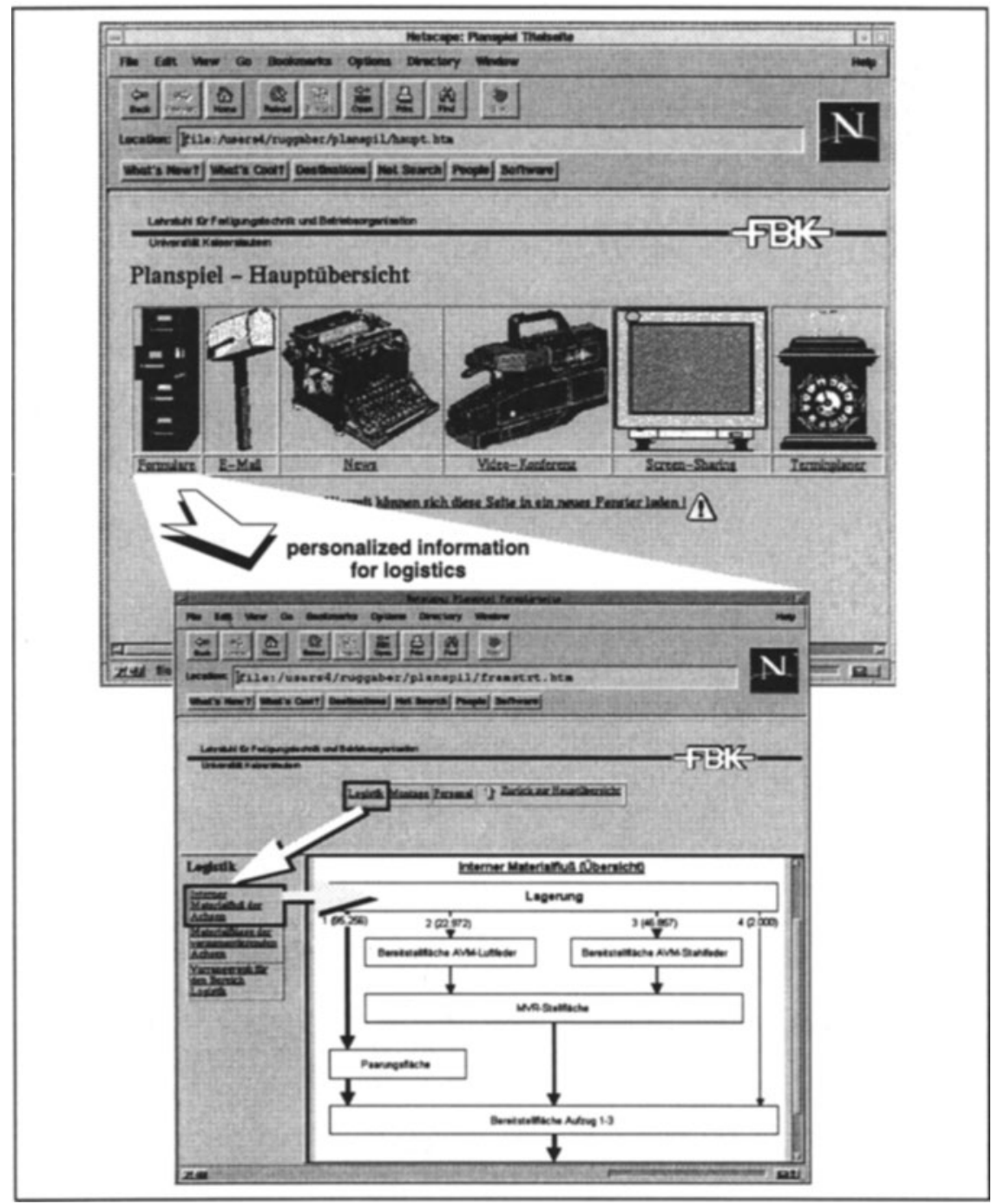

Figure 6: Implementation of personalized information supply using WWW-technology. 
- Did the students use different communication tools for the same problem? Did an evaluation for the best method take place in the group?

The learning effect influenced the usage of ICT. In the beginning, video has been a very important tool to socialize. After the forming and storming phase, the group concentrated on application sharing, news group and audio-conferences to support the performing of the game. Different applications were used for specific tasks which showed a learning during the game.

- Which conflicts occurred? Were they due to the distance between the members of the group? Were these technical problems caused by the communication tools? Or were these social problems?

Only technical influenced problems occurred. Due to the fact that the bandwidth in the Internet can't be reserved, the video conferencing session often ended with a network break-down. Also whiteboard sessions were influenced by small bandwidth: Sometimes the group couldn't receive all signals on the whiteboard which caused misunderstandings.

- Was it possible to design a Group Knowledge Based Management System for the group and what were the main restrictions to fulfill this?

The students did not put together all their information in a shared knowledge database. Therefore they used the newsgroups to supply everybody with all information and data.

- How much did the results of the distributed groups differ to those of the locally placed groups in Kaiserslautern?

There were no major differences in the results of the groups.

All evaluations led to the conclusion that the planning task can be well supported by ICT an fulfilled by distributed teams. For the socializing process a face-to-face meeting at the beginning seems to be necessary to increase the efficiency of the planning task.

\section{KNOWLEDGE TRANSFER}

The changes in the industrial environment mentioned in the introduction are implemented in the game concept and offer the students the possibility to gather practical knowledge and experience.

The compact course should give students a feeling of the potentials and limitations of ICT usage and, more important, demonstrate how important communication for team processes is. This knowledge can only be gathered through experiencing in a compact course, because communication can only be trained in practice and can not be theoretically taught.

After the first stage of implementation in June 1997, the MinePlan concept is planned to be extended to various universities in Europe. The pan-European partici- 
pation will give students the opportunity to work within an international team using the English language to communicate. The students will be placed in an international network in which they can work without moving physically so that a virtual reality with a real life background emerges.

The transfer of this knowledge to industry is first of all realized through the qualification of future engineers and secondly by offering companies the possibility to participate in the compact course, so that direct knowledge transfer can take place.

\section{REFERENCES}

Augustin, H. (1996) Produktionsgestaltung: Interaktion von Arbeitsstrukturierung und Organisationsgestaltung. Vorlesung Sommersemester 1996, FBK, Universität Kaiserslautern.

Augustin, H. and Förster, H. (1996) Reorganisation durch InformationssystemeErgebnisse einer Umfrage zum Verhältnis von Informationssystemen und Reorganisation. Zeitschrift für wirtschaftliche Fertigung, Vol 91, No 10, 498500.

Bauerfeld, W. (1995) Multimediale Telekommunikationsdienste. Office Management, Vol 95, No 5, 18-25.

Dier, M. and Lautenbach, S. (1994) Groupware: Technologien für lernende Unternehmen. Computerwoche-Verlag, München.

Lewe, H. (1995) Computer Aided Team und Produktivität. Deutscher Universitäts Verlag, Wiesbaden.

Warnecke, G. and Augustin, H. (1996) Knowledge Based Information Design of Network Production Segments. Production Engineering, Vol III, No 2, 119 121.

\section{BIOGRAPHY}

Harald Augustin, born in 1967, studied at the Technical University of Karlsruhe, Germany, and abroad in Australia, Canada and France. Since 1993 he works as a research assistant with Prof. Dr.-Ing. G. Warnecke at the Institute of Manufacturing Engineering and Production Management FBK at the University Kaiserslautern, Germany, where he received his Ph.D. (Dr.-Ing.) in July 1997 and where he helds the position of a chief-engineer since 1996. His research subjects are production process modeling and information logistics. 